\title{
Comunicabilidade na rede: chances de uma alteridade medial
}

////////////////// : Ciro Marcondes Filho ${ }^{1}$ 


\section{Resumo}

O ensaio compara formas de comunicação - presencial, telefônica e eletrônica -, tomando como exemplo o rosto e o avatar e a questão da alteridade em formas como o diálogo, a paixão e a comunicação nos discursos de Martin Buber, Emmanuel Lévinas e Vilém Flusser.

\section{Palavras-chave}

comunicação presencial, comunicação eletrônica, rosto, avatar, alteridade, diálogo

\section{Abstract}

The essay compares the ways of face to face, telephone and electronic communication, using the example of face and avatar as well as the question of otherness in ways such as dialogue, passion and communication in the speeches of Martin Buber, Emmanuel Lévinas and Vilém Flusser.

\section{Keywords}

face communication, electronic communication, face, avatar, otherness, dialogue 


\section{Da alteridade}

A discussão da questão da alteridade começa com Ludwig Feuerbach, que dizia que eu, enquanto homem, reconheço a existência de outro ser, diferente de mim e complementar a mim, que colabora para me determinar. $\mathrm{O}$ verdadeiro princípio do ser é o Eu unido ao Tu. Sozinho, o homem não é nada - nem ser moral nem ser pensante — ; apenas na comunidade, na aliança de um ser humano com outro, está contida a essência desse ser humano. Essa comunidade apoia-se na diferença do Eu e do Tu (ARVON, 1998, p. 542).

No princípio, não havia o Eu, mas o Tu: todo início parte de um Tu, diz Martin Buber; ele é a fonte primordial. O que importa é a forma como o homem se relaciona com seu semelhante, como considera esse "outro", como sai (ou como consegue sair) de si e entrega-se à relação a partir do reconhecimento do outro. Todo enigma da comunicação resume-se a isso: a essa capacidade de romper a redoma cartesiana de um solipsismo autossuficiente e autopoiético e acolher o outro, recebê-lo, ousar o diferente. Não foi outra a preocupação de Adorno ao sair em busca do não idêntico: "lembre-se", dizia ele, parodiando o memento mori dos antigos, "há um outro". Adorno vai ao encontro do que destoa, do que não se adapta, do que provoca estranhamento, em suma, do que não sou eu (ADORNO, 1970-1986, p. 161).

Aquele com quem nos comunicamos, com quem conversamos, com quem estabelecemos um diálogo é nosso alter. Lévinas fala 
2. Tempo redescoberto, p. 142.

do rosto do outro como "presença que me põe em xeque", que suscita em mim amor ou ódio, que questiona o reinado feliz do meu ego. É esse rosto, alteridade que se contrapõe ao meu ego, que, na verdade, institui meus limites e minha insignificância e que cria as condições da comunicabilidade. É ele que me força a pensar (LÉVINAS, 1974, p. 204ss).

Proust vê apenas na arte as janelas de nossa intersubjetividade; por ela, podemos sair de nós mesmos, saber o que outrem vê de seu universo, que não é o nosso, assim como conhecer suas paisagens estranhas. Pela arte, diz ele, não temos um só mundo, mas o vemos multiplicar-se e dispomos de tantos "quantos artistas existem" (apud DELEUZE, 1987)². Esse mundo que se descortina com a arte, o vemos, nós, como o mundo da comunicação, inacessível a Proust. Mas Lévinas vai mais longe. Fala que a feminilidade é a alteridade absoluta, total. Feminino, para ele, é a própria alteridade, tanto no sentido da mulher como "acolhimento hospitaleiro do outro" como na relação erótica (LÉVINAS, [s.d.], p. 58).

Assim, eu me comunico quando acolho o outro, quando me esvazio de mim, de minha autossuficiência, quando deixo meu solipsismo e me amplio, me alargo, me supero pelo outro. Com o outro, pode acontecer a mesma coisa, e aí eu passo a ser o outro dele, e ele, o meu. Mas dificilmente essa abertura é mútua; com raridade é realizada a interpenetração das almas. Na maior parte das vezes, ela é unilateral. Na ocorrência da bilateralidade, temos o encantamento ou o fascínio em sua plenitude, como apreciação do outro como mistério e sendo valorizado, a si mesmo, como mistério do outro.

No sexo, cada ser entra em relação com o absoluto outro, uma alteridade imprevisível e desconhecida da lógica formal. O outro vai permanecer sempre outro, jamais vai tornar-se meu. A posse desse outro é ilusória, contingencial, o que dá origem aos ciúmes, à paixão, ao permanente desespero da perda. Eros é profanação, devassidão, usurpação, ato de invadir algo escondido, mas o rosto permanece fechado, insondável, sendo a "recusa da expressão", de que fala Lévinas (2000, p. 176). Ele não perde seu mistério ao ser o corpo desvendado, ele não se revela, não se põe nu. A pessoa que desnudamos se dá e não se dá. 
O corpo do outro não ilumina meu horizonte; a revelação que a nudez traz não desmascara coisa alguma. Só o rosto revela. Revela a recusa do exprimir, releva a infinitude do outro, da alteridade. Em outras palavras: o ato de desnudar o outro não descortina nada, não é significação; o lascivo, conforme Lévinas, é pura in-significância (1998, p. 163-164). A intersubjetividade realizada em Eros é uma proximidade que mantém a distância. Significação, de fato, é a expressão originária, "pré-sígnica" de um rosto que fala por si mesmo, "em pessoa", manifestação do próprio ente, expressão irredutível à compreensão.

Proust frustra-se por não poder capturar o outro. Albertine é a própria prova da instabilidade: o narrador jamais sabe quem de fato ela é ou foi; tampouco nós. No rosto de Albertine há um mistério que ultrapassa a eventual nudez que ela poderia lhe mostrar. Na sua sexualidade (nesse "desconhecido que me perturbou no passado"), a ocorrência é não reveladora, não diz nada da vida devassa de Albertine; é a in-significância de uma proximidade que mantém a distância; no rosto (no "exterior"), no além-sexo como alteridade absoluta, ao contrário, ele encontra a "significação", o contato com a transcendência.

Quando Lévinas fala do feminino, ele não está pensando nas mulheres. Feminino é um medium que nos põe em contato com a infinitude, com a transcendência. É “intersubjetividade assimétrica”, que reduz as dimensões de meu ego e me introduz numa relação antes de enriquecimento, comunicacional com o outro.

\section{O diálogo e a rede}

Diálogo é a primeira forma de comunicação humana. Mas não o diálogo interior, a "vida solitária da alma", como o vê Husserl, origem de todas as significações de palavras e frases, senão o aparecimento de um Tu que justifica e constitui a existência de um Eu. Logos, etimologicamente, é uma "palavra que atravessa", que alinhava, que liga, que amarra os envolvidos na conversação, dia-logos. Lugar de encontro, espaço "entre", dimensão que faz 
par com o "durante", na ocorrência do aqui e do agora da relação dialógica. Para Buber, o entre é o lugar onde o espírito habita, algo que acontece entre pessoas, inclusive no amor: o homem habita o amor, como habita a linguagem. Eu não possuo o outro, não o submeto, mas, considerando a alteridade tout court (o feminino), eu o acolho, o recebo, o hospedo, o trago para dentro de mim. Ao contrário, quando submeto o outro, cria-se o tédio, o desinteresse.

O campo da fenomenologia é o que mais acredita no diálogo. De um lado, Merleau-Ponty, que corrige os excessos subjetivistas de Husserl, que atribuía à consciência a determinação de toda a significabilidade; de outro, Emmanuel Lévinas, que enxerta o conceito do diálogo com um componente ético. Ele reconhece a existência desse "espaço entre" e desse "tempo durante" que constituem o diálogo, mas investe mais diretamente na ontologia dessa relação. Não há "fundamento gnosiológico" aí, quer dizer, eu não me relaciono com o outro para aprender, conhecer, pesquisar, saber. Isso cabe às relações Eu-Isso. Só o Tu como absolutamente outro pode me conduzir à comunicabilidade, ao novo na minha existência, àquilo que me transforma. $\mathrm{O}$ outro é alguém que não tem nada a ver com meu procedimento subjetivo, é estranho a mim, põe-se diante de mim.

Por isso, em comunicação, emissão não tem nada a ver com recepção. Eu emito, todos emitem, o mundo é um festival incansável de sinais aspirando ser recebidos, incorporados, lidos, reconhecidos. Mas poucos o são. O que eu abro para o mundo, a pequena fresta tangencial que me põe em contato com a realidade externa, é uma janela cuidadosa, cautelosa, discreta. Eu observo esse sinal (é a minha intencionalidade), eu autorizo seu ingresso em meu sistema receptivo, sinal esse que agora, então, torna-se informação ou comunicação (essa autonomia da minha decisão será, contudo, relativa, como veremos no próximo item).

Eu e Tu somos figuras insondáveis. O diálogo confirma isso, desdobrando uma distância absoluta entre nós, como diz Lévinas. Eu e ele somos únicos, distintos, diferentes, nada nos é comum nem há lugar para qualquer coincidência; não obstante, o diálogo supera a distância sem suprimi-la: chego ao outro sem explorá-lo, sem investigá-lo, sem escavá-lo. 
Modernamente, Vilém Flusser busca recuperar o diálogo. Diferentemente do que propõe a função ética levinasiana do diálogo - em que "eu me torno servo do outro" -, Flusser atribui uma função existencial a esse diálogo, a da busca do sentido: com ele, pretende-se esquecer o sem-sentido e a solidão de uma vida voltada para a morte. Os ecos heideggerianos aqui são inegáveis; já seu conceito de diálogo deriva diretamente de Buber.

Vilém Flusser considera a situação atual, em que as pessoas, envolvidas em tecnologias virtuais e em aproximações mediadas por computador, perdem a "consciência social". O tecido social desfaz-se em grãos; essa trama e as ligações se corroem, porém não deixa de haver sociabilidade, diz ele, pois há uma forte socialização, mas em outro sentido. Ocorre um trânsito de imagens e de pessoas que apresenta sinais de entropia, tornando a sociedade isoladora e massificadora; mas há outros meios, mais animadores, "que atravessam o feixe de raios que ligam imagens e homens, as linhas dialógicas, que, comutados de forma inversa, transformam tecidos fascistas em tecidos em rede, democráticos, criando, assim uma sintonia comum obrigatória. O diálogo acontece aí, nessa 'conversa cósmica"' (FLUSSER, 1998, p. 71-72).

O pesquisador tcheco pensa, contudo, num diálogo digital, uma forma de comunicação em que o presencial seria substituído pelo eletronicamente mediado, em que esse outro que eu acolho e que estranho está lá, nas redes telemáticas, se bem que nebuloso, sem formas e sem nome, apenas como um avatar, algo que simula um ser humano. Essa simulação pode ser obra da "inteligência artificial", como já pretendiam os antigos jogos de Alan Turing, mas imaginemos que esse outro possua uma existência concreta, apesar de eu não poder capturá-la. Essa existência jamais irá aparecer no mesmo plano e na mesma condição em que me encontro aqui, neste momento, física e materialmente operando diante de um computador. Logo, o diálogo cósmico é um diálogo desigual, em que cada lado "constrói" imaginariamente a alteridade do outro, seu "rosto" virtual, que jamais poderá me advertir do "Não matarás!". Ao contrário, é um rosto perfeitamente passível de assassinato, visto que o apagamento de sua imagem é um fato inconsequente, trivial. 


\section{Rosto, avatar, paixões}

$\mathrm{Na}$ vida social, agimos de forma reservada, nos policiamos, especialmente se o outro puder nos rever, nos rastrear, nos encontrar. Quando esse outro for alguém que jamais cruzará conosco, então estaremos liberados para representar o papel que quisermos, inclusive o nosso próprio. Confessar, revelar, expor-se, desnudarse espiritualmente durante uma corrida de táxi pode ter como resultado descargas, alívios, relaxamento, até mesmo jogo, mas não encerra comunicabilidade. O mesmo ocorre com a conversa com estranhos nos ambientes virtuais.

Um avatar não é um rosto. $\mathrm{O}$ rosto que eu acolho em mim e que me traz a diferença é o rosto que finalmente me comunica. É um rosto da presença. No presencial e pelo contato com o outro, eu entro em fase com aquilo que irá acionar em mim dispositivos de transformação. Mas nem sempre a vida em sociedade permite que meu rosto seja conhecido, menos ainda que ele ocupe, enquanto alter, o espaço vazio posto à minha disposição por um Tu, aguardando que, comigo, chegue à ocorrência comunicacional. As pessoas nem sempre podem se encontrar, e meu segredo tem dificuldades em comunicar o diferente ao outro. Daí, o fato de que a construção de um avatar, protegido pela assepsia da tela, poderia, potencialmente, abrir espaços para que o outro me procure. Mostrando-me espiritualmente nu, meu avatar me revelaria, seria expressão originária, "pré-sígnica”, de um ser que fala por si mesmo, sem máscaras. Ora, mas não é bem assim.

Entre presença, conversa telefônica e diálogo na rede, há diferenças profundas. No primeiro caso, todos os sentidos - visão, audição, percepção dos humores, das oscilações de temperatura, de emoção, do élan do outro - estão presentes, a comunicação é plena. No segundo, sobrevive apenas o sentido da audição, acompanhado da percepção das reações, do estado de espírito, do clima “do outro lado". No terceiro, quase tudo isso desaparece: passa apenas a ser imaginado pelas frases que são trocadas na tela do computador.

A internet consolidou-se como um amplo espaço da comunicação escrita. Diferentemente da previsão dos anos 1980, 
que prognosticava uma humanidade "disléxica", incapaz da leitura, que operaria apenas com ícones eletrônicos, o que se vê hoje, ao contrário, é antes um tipo de hidrocefalia da escrita, na qual a escrita absorve as outras linguagens na medida em que tenta representar humores, excitações, risos etc. A linguagem verbal, as imagens transmitidas por uma webcam são pouco utilizadas. Talvez porque a comunicação escrita mantenha melhor a distância, ou seja, a não identificação, a fuga do olhar e do rosto do outro, típicas de um tipo de recolhimento e de manutenção da anonimidade que acontece na rede.

O rosto, em Lévinas, vai muito além do rosto. Ele fala por si, é pura manifestação do ente, expõe cruamente nossa existência, suscita amor ou cólera, questiona meu ego, me deixa sem palavras. Ele não é o discurso sobre um ferimento, ele é o próprio ferimento aberto, exposto, cratera da interioridade. $\mathrm{O}$ outro me é infinito, inatingível; apenas percebido, cruelmente impregnando em mim. Nas rugas do rosto, afloram os rastros de um si mesmo, de sua máscara, de seu vazio. Ele não é o dito, é o dizer, o verbo no infinitivo, plena sinceridade, expressão sem conceitos. Por tudo isso, ele mexe comigo, me incomoda, eu não o entendo. Mas ele é também o oposto do amor: é assimetria e "não fusionalidade", assim como o oposto da nudez. A nudez não desmascara nada, não ilumina horizonte algum, nada se descortina com ela; a nossa distância se mantém. E o que acontece com o avatar, com essa nudez construída, esse despojar-se eletrônico? Será que ocorre uma comunicabilidade?

No avatar, eu me mantenho vestido, mas me dispo de meus atributos físicos; meu discurso já não é mais corpo produzido culturalmente pela moda, pelos costumes, pela estética do momento, mas apenas um discurso despido. Eu mostro-me além da vestimenta, além da aparência; mostro-me aparentemente como ente. Mas eu estou buscando a fusão quando procuro o amor, o sexo; logo, não posso ser rosto, que é "não fusionalidade". Meu corpo tampouco fala por si; eu o construo pela linguagem. Ele é um "dito", um formato culturalmente impregnado, é discurso sobre o amor e sobre a dor, não é eles mesmos. Ele não é, menos 
ainda, transparência pura, linguagem sem signos, "a-sígnica", mas veículo de minha autopropaganda. Ele não mexe com o outro, incomodando-o; ele seduz o outro pelos signos da aproximação e do acoplamento, buscando a simetria. Daí a aporia da proposta de Flusser: enquanto diálogo, a comunicabilidade eletrônica perde de vista isso, faz o rosto do outro desaparecer nas trocas digitais.

Nesse último caso, podem ser desenvolvidas verdadeiras "amizades virtuais", que aprofundam o grau de intimidade entre os interlocutores exatamente pela facilidade que permite a máscara, o avatar. A garantia de "irrastreabilidade" libera relações ditas "puras", em que abrimos ao outro fatos e informações que, na cena cotidiana, concederíamos a muito poucos, talvez a ninguém. O outro virtual não é um padre a quem me confesso, pois este último me ouvirá com intenção de me julgar e de me exigir arrependimentos e submissão; tampouco é um terapeuta ou um analista, que me ouvirá para localizar em mim sintomas. É meu duplo, espécie de outro eu, do lado de lá da tela, que ouve meus diálogos interiores e os aceita ou os critica. Extensão de mim e de meu solipsismo, que anula a alteridade e vê o mundo como caixa de ressonância de minhas próprias impressões.

Por não ter rosto, jamais me desafiará. Se um dia marcarmos um encontro, e eu puder ver esse rosto, surgirá daí uma outra relação, absolutamente distinta da anterior, já que a alteridade agora constituída tanto questiona meu ego autossuficiente e seu duplo quanto se apresenta numa nova dimensão, a da presença, do rosto, daquilo que me será sempre insondável.

Há pessoas que se apaixonam por outras na internet apenas a partir do discurso. A sedução das palavras preenche aspirações desejantes do outro, e é possível que na vida real esse sentimento continue, exatamente porque a mesma máscara continua a ser usada. É precisamente a diferença entre a paixão e a comunicação, visto que a primeira é um processo (ou busca) de captura, enquanto a segunda é o inverso, é um processo de cessão. Acolher o outro não é entregar-se a ele. A servidão de que fala Lévinas é servidão por reconhecimento do mistério do outro, servidão em que eu me engrandeço esvaziando meu ego e 
elevando o outro (LÉVINAS, 2002, p. 201). Na paixão, esse outro que ocupa meu ego e toma conta de toda a minha existência não me eleva, mas me faz servil do meu próprio sentimento, que se fundiu a ele. Ele é obra de minha insanidade, não o confronto com algo que me abre para o desconhecido.

A comunicabilidade do outro como alguém que nos é desconhecido é improvável. Raramente ultrapassamos os sinais rituais das trocas fáticas; quando o fazemos, nos colocamos no campo de uma comunicabilidade com intenções outras, que não são exatamente as de comunicar. Porque buscamos compreender, decifrar, enquadrar o outro, seduzi-lo. Diferente é quando esse outro escapa-nos o tempo todo, mas não da forma fugidia dos encontros assustados e que acontecem por estarmos inseguros; escapa-nos, os provocando-nos sempre. Esse outro da presença é essa densidade de percepções do diálogo direto, apontada acima. Essa é uma experiência insubstituível. Não há nenhuma forma eletrônica, menos ainda irradiada, que ocupe seu lugar, que a substitua à altura. Por isso, a comunicação mediada por computador é uma comunicação de outra natureza, com elementos e construções próprios.

Pelo computador, eu posso me comunicar com alguém muito conhecido, íntimo meu, posso conversar com pessoas que eu conheço medianamente e com desconhecidos. Quando falo com minha amada por computador, eu junto suas frases e simulo sua presença ao meu lado a partir das informações dela que eu reuni na memória. É um diálogo misto, pouco inovador e com comunicabilidade mínima, se considerarmos as condições propostas por Lévinas. Trata-se de uma forma redundante de interlocução. Imaginemos o outro extremo, o do avatar.

Não há como compatibilizar dois fenômenos que são estranhos um ao outro. A tecnologia irá aprimorar cada vez mais suas máquinas de reprodução do real. A tela nos trará brevemente não apenas o texto da pessoa com quem conversamos mas também sua voz e sua imagem, em tempo real e em alta definição, igual a que temos no contato físico e direto, ou ainda melhor do que ela. Mas a variável tecnologia ainda estará presente e 
continuará a criar uma relação diferente entre mim e o outro. Isso porque o componente da experiência comunicacional deixa de estar presente: a cena, a atmosfera, o clima, o espaço entre, a dimensão invisível mas operante do terceiro elemento, espaço de jogo de energias, de fluxos, espaço de circulação de fantasmas. A eletrônica limpa tudo isso, remove a mística do encontro e nos permite a fala sem mediações metafísicas. Ela torna o mundo um encontro asséptico, purificado, livre, mas seguramente menos ricos e enigmático que a comunicação interpessoal. 


\section{Referências}

ADORNO, T. W. "Negative dialektik". In: ADORNO, T. W. Gesammelte Schriften. Frankfurt: [s.n.], 1970-1986.

ARVON, H. Verbete "Feuerbach". In: DICTIONNAIRE DES PHILOSOPHES. Paris: Albin Michel, 1998.

BUBER, M. Eu e Tu. Tradução, introdução e notas de Newton Aquiles von Zuben. São Paulo: Centauro, 2004.

DELEUZE, G. Proust e os signos. Tradução de Antonio Carlos Piquet e Roberto Machado. Rio de Janeiro: Forense-Universitária, 1987.

FLUSSER, V. "Ins universum der technischen bilder". European Photography, Göttingen, n. 6, 1999.

Kommunikologie. Frankfurt: Fischer, 1998.

LÉVINAS, E. Autrement qu'être ou au-delà de l'essence. [S.l.]: Kluwer Academic, 1974.

. De l'existence à l'existant. Paris: Vrin, 1998.

. Ética e infinito: diálogos com Philippe Nemo. Lisboa:

Edições 70, [s.d.].

- "O diálogo: consciência de si e proximidade do próximo”. In: LÉVINAS, E. De Deus que vem a idéia. Tradução de Pergentino Stefano Pivatto. Petrópolis: Vozes, 2002.

Totalidade e infinito. Tradução de José Pinto Ribeiro.

Lisboa: Edições 70 [2000].

MERLEAU-PONTY, M. Phénoménologie de la perception. Paris: Gallimard, 1945. 


\section{NORMAS PARA PUBLICAÇÃO}

\section{Objetivos da publicação}

Significação - Revista de Cultura Audiovisual publica artigos e resenhas dedicados ao estudo do cinema, do vídeo, da televisão, do rádio e das mídias digitais, pensando-os como um sistema diversificado de práticas e ideias que envolvem os seus processos específicos de reflexão, criação, produção e difusão.

A revista é semestral e aceita trabalhos originais e inéditos (de autoria individual ou coletiva) de autores(as) com titulação mínima de doutor, em sistema de fluxo contínuo. É possível aceitar textos de doutorandos(as), desde que em coautoria com doutores/as. Os textos enviados não poderão ser submetidos a outras publicações.

\section{Processo editorial}

Para participar do processo editorial os textos devem ser enviados como anexo para o email: significacao@usp.br

Os artigos submetidos ao Conselho Editorial que não atenderem às exigências mínimas previstas nas normas não participarão do processo de avaliação. Todos os artigos recebidos são analisados e enviados ao processo de avaliação por membros do conselho e consultores ad hoc, com integrantes no Brasil e no exterior, em sistema de avaliação cega (sem identificação de autoria) conforme 
afinidade temática. O processo de avaliação leva de 4 a 8 semanas, e seu resultado é comunicado por e-mail aos autores/as, que serão notificados sobre aceitação ou recusa do texto, ou receberão uma solicitação para realizar modificações. As mudanças estão sujeitas a nova apreciação e submissão do artigo. Em caso de aprovação, o texto passa por revisão ortográfica e gramatical, com possível contato com os/as autores/as para solução de dúvidas. Após revisão e diagramação, os artigos são publicados na edição indicada da revista, e seus autores, avisados da publicação por e-mail. O momento da publicação das contribuições recebidas será decidida pelo Conselho Editorial.

\section{Cessão de direitos}

$\mathrm{O}(\mathrm{s})$ autor(es) devem enviar um termo de cessão de direitos de publicação, em que conste seu(s) nome(s) completo(s) e seu(s) endereço(s), sendo de sua responsabilidade obter e apresentar permissão para reproduzir imagens, ilustrações, tabelas, gráficos etc. Cabe também ao(s) autor(es) a obtenção da aprovação de comitês éticos em artigos que envolvam pesquisas com seres humanos.

\section{Cabeçalho}

- Título do trabalho, centralizado e em negrito, em português e em inglês, em fonte Times New Roman, tamanho 12.

- Nome(s) do(s) autor(es) e, como nota de rodapé, minicurrículo(s), com titulações e local(is) de trabalho (até quatro linhas), seguidos de endereço de e-mail, em fonte Times New Roman, tamanho 12.

- Resumo (até 7 linhas) e palavras-chave (até cinco), em fonte Times New Roman, tamanho 12.

- Abstract (até 7 linhas) e keywords (até cinco), em fonte Times New Roman, tamanho 12. 


\section{Formatação}

Os textos deverão ser submetidos da seguinte forma:

- $\quad$ Arquivo em programa word (.doc) ou compatível (.rtf).

- Espaçamento 1,5, formato A4, fonte Times New Roman, tamanho 12.

- Texto corrido, sem recuo a cada parágrafo e sem espaço entre parágrafos.

- Títulos e subtítulos devem ser destacados em negrito (com espaço antes deles).

- Destaques ao longo do texto devem ser feitos em itálico.

- Nome do arquivo com o sobrenome do autor principal.

O texto deve ter 15 a 20 páginas, incluídos nesse limite título, resumo, abstract, ilustrações, notas e bibliografia.

\section{Ilustrações (fotografias, desenhos, figuras, quadros, gráficos e tabelas)}

- Devem estar no corpo do texto e também ser enviadas digitalizadas isoladamente, em arquivo separado, com as devidas fontes de referência.

- Formato de digitalização em .tiff, .bmp ou .jpeg, com resolução mínima de 72.

- Largura mínima de 4,4 cm.

- A revista Significação reserva-se o direito de não publicar o material ilustrativo que não esteja adequado a essas orientações.

- Para elaboração de gráficos, quadros e tabelas, dar preferência aos programas word e excel.

- Títulos e legendas devem estar imediatamente abaixo das figuras e dos gráficos e imediatamente acima dos quadros e das tabelas. Todos deverão estar numerados consecutivamente, em arábico. 
- De acordo com a lei de direitos autorais, as fotos e os desenhos devem vir acompanhados dos nomes de seus autores. Em caso de o(s) autor(es) não ser(em) o(s) mesmo(s) do artigo, os primeiros devem assinar uma autorização para publicação, ou $\mathrm{o}(\mathrm{s})$ autor(es) do artigo devem se responsabilizar (por escrito) pela publicação. Isso não se aplica a imagens antigas cujos direitos autorais já expiraram.

\section{Notas de rodapé (somente as explicativas)}

- Devem vir em tamanho 9.

Exemplos:

Certo: Atualmente existem mais de 300 unidades fechadas de...

Errado: ESTRADA, S. Previdência social e complementar e os mercados comuns, p. 13 (trata-se, nesse caso, de uma citação referencial).

\section{Citações referenciais}

- Identificar as referências (em parênteses) no texto, colocando o sobrenome do autor (com todas as letras em maiúsculo), o ano e, quando necessário, a página.

Exemplos:

Um autor: (WENTH, 1998, p. 12); dois autores: (LAMARE; SOARES, 1990, p. 134-135); três ou mais autores: (HARRIS et al, 1998, p. 26).

- As citações referenciais não vão em nota de rodapé, mas no corpo do texto, logo após o trecho citado. Exemplo: (KELSEN, 1979, p. 91).

- Citações com mais de quatro linhas deverão vir em parágrafo específico, com recuo de $4 \mathrm{~cm}$ e tamanho 10 .

- Não usar Idem ou Ibidem. 


\section{Referências}

A lista de referências deve estar em ordem alfabética, de acordo com as normas ABNT (6023 e 10520).

Exemplos:

- Formato para livros

CALDWELL, J. T. Televisuality: style, crisis, and authority in American television. New Jersey: Rutgers, 1995.

- Prenomes dos autores abreviados; maiúscula apenas na primeira letra do título; não utilizar prenomes em editoras, desde que isso não comprometa a identificação.

- Subtítulo em minúscula e depois de dois pontos.

- Formato para teses e dissertações

MUANIS, F. As metaimagens na televisão contemporânea: as vinhetas da Rede Globo e MTV. Tese (Doutorado) - Universidade Federal de Minas Gerais, Belo Horizonte, 2010.

- Formato para artigos

PAIVA, S. "A propósito do gênero road movie no Brasil: um romance, uma série de TV e um filme de estrada". Rumores, São Paulo, v. 1, n. 6, set.-dez. 2009.

- Formato para trabalhos apresentados em eventos

REGUILLO, R. "El lenguaje e los narcos”. In: SEMINARIO NARCOTRÁFICO Y VIOLENCIA EN CIUDADES DE AMÉRICA LATINA: retos para un nuevo periodismo, 2009, México. Anais eletrônicos... México: FNPI, 2009. Disponível em: <http://cosecharoja.fnpi.org/wp-content/uploads/2010/09/ Seminario_Narco.pdf $>$. Acesso em: 15 ago. 2011. 